\title{
Paper
}

\section{Mechanical Properties of Ni-Free High-Nitrogen Austenitic Stainless Steel Made by Metal Injection Molding with Nitrogen Absorption Method}

\author{
Yosuke Aoyama ${ }^{\text {t } 1}$, Midori Komada ${ }^{\text {क } 2}$, Yoshikazu Kuroda ${ }^{\text {t3 }}$, Teruo Takahashi ${ }^{\text {tr }}{ }^{4}$, \\ Noriyuki Tsuchida ${ }^{\text {1 }}$, Yasunori Harada ${ }^{\text {in } 1}$ and Kenzo Fukaura ${ }^{\text {in } 1}$ \\ ${ }^{4} 1$ Graduate school of Engineering, University of Hyogo, 2167 Shosha, Himeji 671-2201, Japan. \\ ${ }^{25}$ Kobe Material Testing Laboratory Co.LTD, 47-13 Niijima, Harimacho, Kako-gun, Hyogo 675-0155, Japan. \\ ${ }_{4}^{3}$ Gauss Co.LTD, 237-1 Kamidoi, Yano, Aioi 678-0092, Japan. \\ ${ }_{4}^{4}$ Hyogo Prefectural Institute of Industrial Research, 240-1 Fuke, Hirata, Miki 673-0405, Japan.
}

Received December 22, 2008

\begin{abstract}
SYNOPSIS
Microstructure and mechanical properties of high nitrogen steels containing $17 \mathrm{Cr}-12 \mathrm{Mn}-3 \mathrm{Mo}$ produced by means of metal injection moulding and nitrogen absorption methods were examined. The compacts were sintered at $1300^{\circ} \mathrm{C}$, then furnace-cooled to $1200^{\circ} \mathrm{C}$ and were held at that temperature for 2 to $20 \mathrm{hrs}$. Subsequently, they were furnace-cooled. Thereafter, solution treatment was done at $1200^{\circ} \mathrm{C}$. The solution treated compacts held at $1200^{\circ} \mathrm{C}$ for above $5 \mathrm{hrs}$ had homogeneous microstructure. Increasing the holding time at $1200^{\circ} \mathrm{C}$, ferrite phase disappeared due to the increment of nitrogen content and grain size became larger. Lattice constant of austenite phase also increased. Yield and tensile strength increased with increasing nitrogen content. Yield and tensile strength of the compact held at $1200^{\circ} \mathrm{C}$ for $10 \mathrm{hrs}$ were $758 \mathrm{MPa}, 1172 \mathrm{MPa}$ respectively and elongation was $41 \%$. However, ductile-brittle transition (DBT) behaviour was seen, and the DBT temperature of every compact was about $-20^{\circ} \mathrm{C}$. From the fracture surface analysis, brittle fracture surface was identified as (111).
\end{abstract}

KEY WORDS

nickel-free austenitic stainless steel, high nitrogen, mechanical properties, metal injection molding

\section{Introduction}

In austenitic stainless steels like SUS316 which are used for biomaterials in medical devices such as artificial joints, wires and dental implants, nickel is contained which causes allergic reaction to human beings. It is reported that nickel free high nitrogen austenitic stainless steels have superior mechanical properties, toughness, nongmagnetic characteristics and corrosion resistance than conventional stainless steels. However, it is difficult for the high nitrogen steels to produce small medical implants because of its poor formability. As for the methods of nitrogen addition to stainless steels, pressurized nitrogen gas electro-slag remelting method, mechanical alloying method, and nitrogen gas absorption (NA) method have been investigated. Within these methods, the advantage of NA method is that the HNS can be produced by simple treatment. However, it is difficult for bulk steels to possess fine-grained structure because heat treatment temperature is very high. For sintered compact which has several percentage porosities, it is expected that nitrogen absorption will occur inside the compact resulted in promotion of nitriding. Metal injection molding is especially useful for making near net shape small parts ${ }^{1}$. In this study, high nitrogen austenitic stainless steels were tried to fabricate by the combination of the MIM and the NA method and the microstructure and strength were investigated.

\section{Experimental}

Gas-atomized powder ( $\mathrm{Fe}-17 \mathrm{Cr}-3 \mathrm{Mo}-12 \mathrm{Mn}-\mathrm{N}$ in mass\%) was used in this study. It is difficult for austenitic steel containing $\mathrm{Mn}$ to transform to $\varepsilon$-artensite by sever deformation ${ }^{2)}$, on the other hand, $\mathrm{Mn}$ is also known as a element to degrade the corrosion resistance ${ }^{3)}$. The weight percentage of $\mathrm{Mn}$ is decided in consideration of the matters as mentioned above. Powders were mixed with plasticizer. After blending, compacts were injection moulded. These green compacts were degreased in nitrogen gas, and then they were heated to $900^{\circ} \mathrm{C}$ in vacuum and were held at that temperature for $2 \mathrm{hrs}$ to deoxidize. Nitrogen gas was introduced at $1250^{\circ} \mathrm{C}$. Sintering was done at $1300^{\circ} \mathrm{C}$ for $3 \mathrm{hrs}$. After sintering, compacts were furnace cooled to $1200^{\circ} \mathrm{C}$ and held for 2, 5, 10 and $20 \mathrm{hrs}$ for absorbing nitrogen sufficiently. After nitriding, solution-treated was done at $1200^{\circ} \mathrm{C}$. Sintering was done using $\mathrm{MgO}$ as a setter and $\mathrm{BN}$ as a box material ${ }^{4}$. Microstructure of solution treated compacts was examined by using optical microscope, 
TEM, EPMA, and X-ray diffraction equipments. Mechanical properties of the compacts were investigated by Vickers hardness tests, tensile tests and Charpy impact test. Fractured surfaces were examined by using SEM.

\section{Results and discussions}

The every solution-treated compact consists of austenite single phase although the micro-structure of the compacts held at $1200^{\circ} \mathrm{C}$ for various times and then furnace-cooled was constructed by austenite phase, ferrite phase and nitride. Fig. 1 shows the microstructure of compact held at $1200^{\circ} \mathrm{C}$ for $2 \mathrm{hrs}$. Black areas are pores and the percentage of porosity is $2 \sim 3 \%$ for every compact. The grain size was about $100 \mu \mathrm{m}$ and it became slightly larger with increasing holding time at $1200^{\circ} \mathrm{C}$. Fig. 2 shows the X-ray diffraction patterns for every compact. It shows that ferrite powder transformed to austenite because the compact absorbed nitrogen during sintering under nitrogen atmosphere. Needless to say, nitrogen is austenite former

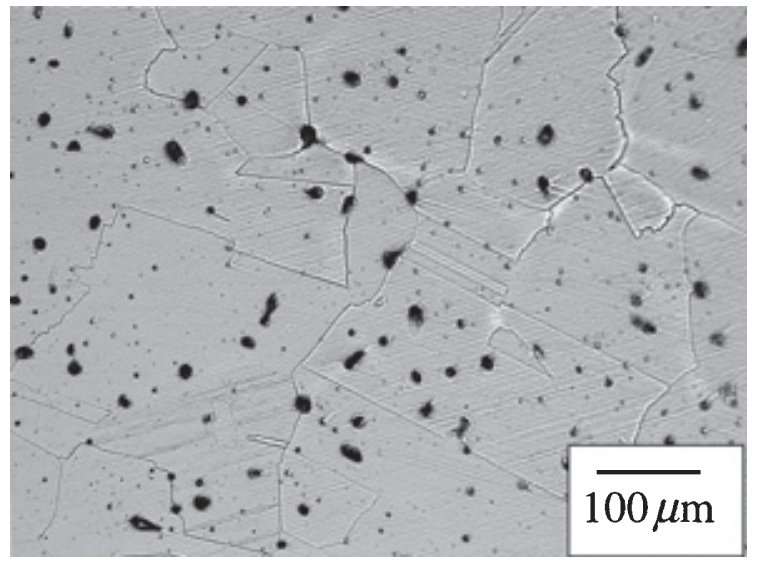

Fig.1 Microstructure of sintered compact held at $1200^{\circ} \mathrm{C}$ for $2 \mathrm{hrs}$.

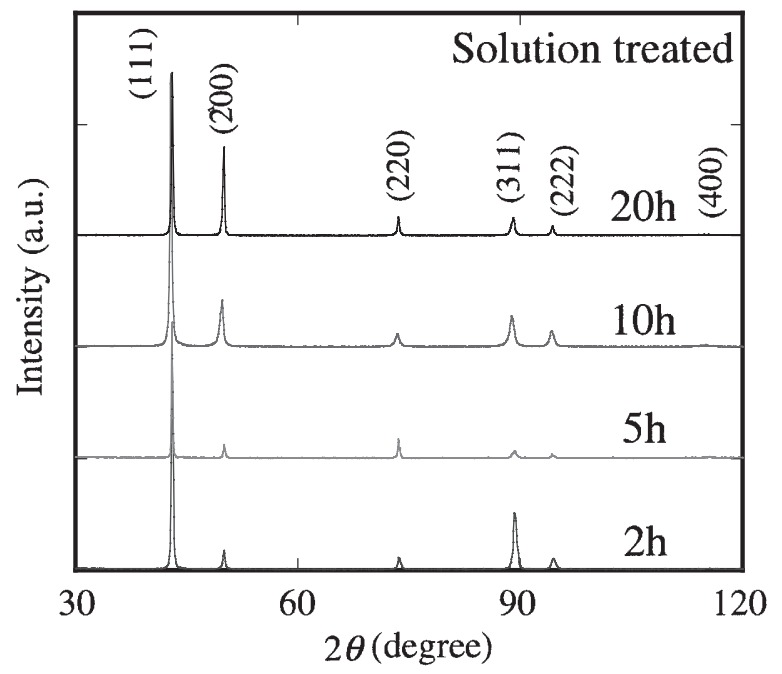

Fig.2 XRD for every compact. element and the austenite structure becomes stable at room temperature. Fig. 3 shows the nitrogen content and lattice constant as a function of holding time at $1200^{\circ} \mathrm{C}$. It is found that they increase with increasing the holding times and then saturate. $\mathrm{N}-\mathrm{K} \alpha \mathrm{X}$-ray images for every compact are shown in Fig. 4. Nitrogen concentration near specimen surface is higher than that of the inside of the specimen until holding time reaches to $10 \mathrm{hrs}$ and thereafter, nitrogen is distributed uniformly throughout the specimen. Fig. 5 shows normal stress-strain curves. Increasing the holding time, that is, increasing nitrogen content, tensile strength

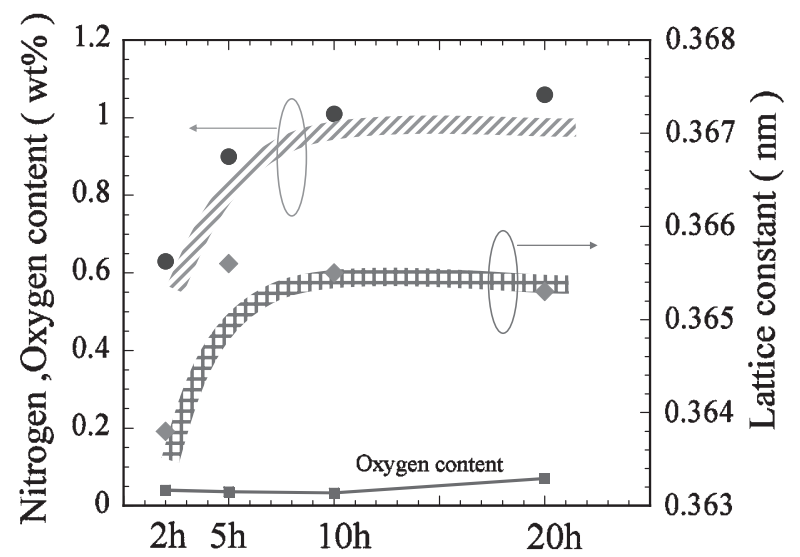

Fig.3 Nitrogen, oxygen and lattice constant as a function of holding time at $1200^{\circ} \mathrm{C}$.
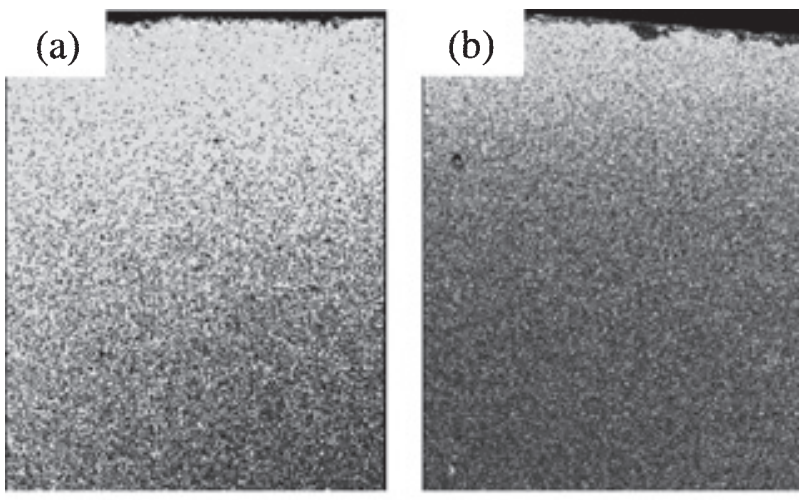

\section{(c)}
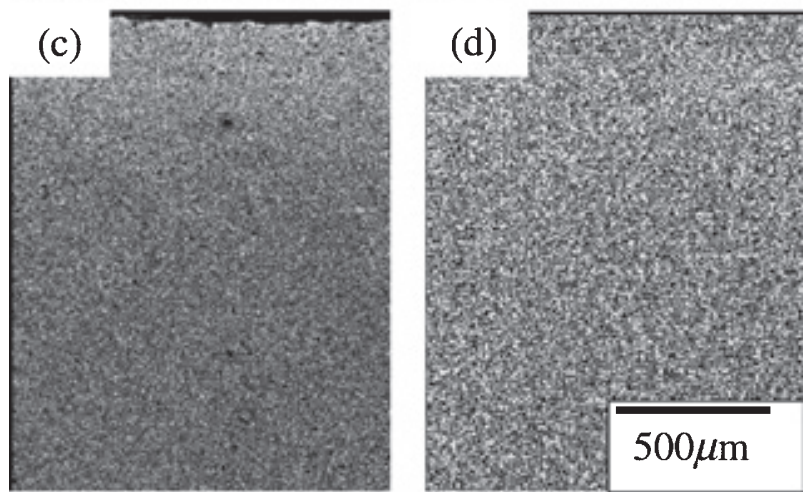

Fig.4 N-K $\alpha$ distribution for $2 \mathrm{hrs}(\mathrm{a}), 5 \mathrm{hrs}(\mathrm{b}), 10 \mathrm{hrs}(\mathrm{c})$ and 20 hrs (d) of $1200^{\circ} \mathrm{C}$. 


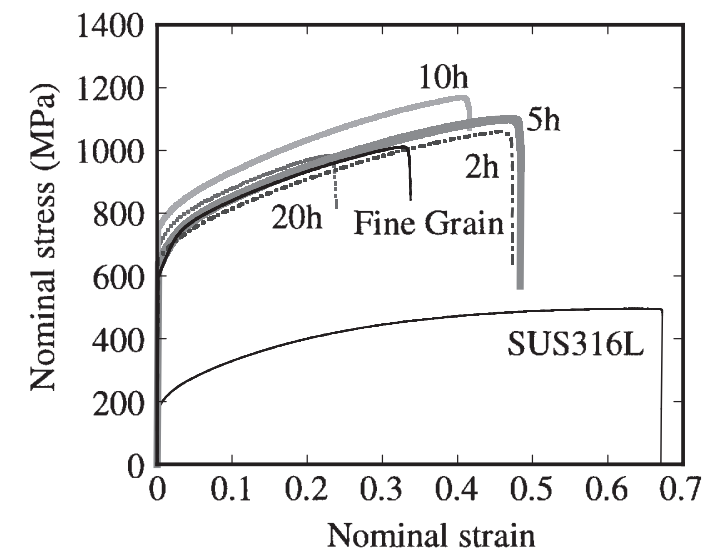

Fig.5 Stress-strain curves of high nitrogen steel held at $1200^{\circ} \mathrm{C}$ for various times and conventional SUS316 made by MIM.

and yield strength increase, inversely, the ductility decreases. Especially, reduction of ductility is remarkable for the compact held for $20 \mathrm{hrs}$. However, high nitrogen steels fabricated by MIM have the good balanced mechanical properties. For example, the compact held at $1200^{\circ} \mathrm{C}$ for $10 \mathrm{hrs}$ has high yield strength of $758 \mathrm{MPa}$ and tensile strength of $172 \mathrm{MPa}$ with a proper fracture elongation of $41 \%$. This is in good agreement with the results of the work done by Uggowitzer et. ${ }^{1)}$, who investigated the mechanical properties of $\mathrm{Ni}$-free austenitic stainless steels made by MIM.

The S-S curve of fine-grained compact whose grain size is $42 \mu \mathrm{m}$ is shown in the same figure. To get the fine grain, the compact held for $10 \mathrm{hrs}$ was exposed to $900^{\circ} \mathrm{C}$ for $5 \mathrm{hrs}$, then cooled. The microstructure was fully covered with lamella structure which consists $\alpha+\mathrm{Cr}_{2} \mathrm{~N}$ phase. Reheating it to $1200^{\circ} \mathrm{C}$, and then quenching, the fine-grained austenic microstructure can be obtained. The reason of refining the grain is that the lamella structure provides the number of nuclei of austenite. For the detailed interpretation, the reader is referred to papers by Tsuchiyama ${ }^{5}$. As usual, decreasing the grain size, yield strength should increases according to the Hall-Petch equation. And it is well known that the rocking parameter $k$ in the equation is very high for high nitrogen steels. However, the yield strength of fine-grained compact decreased in comparison with that of coarse grained one and also fracture elongation deteriorated. The reason why tensile properties degraded might be due to the denitriding during additional heat treatment which was done under the atmosphere. The detail is re-examined continuously. Now, the several strengthening mechanisms by nitrogen solid-solution are suggested; formation of I-S pair, short range ordering of

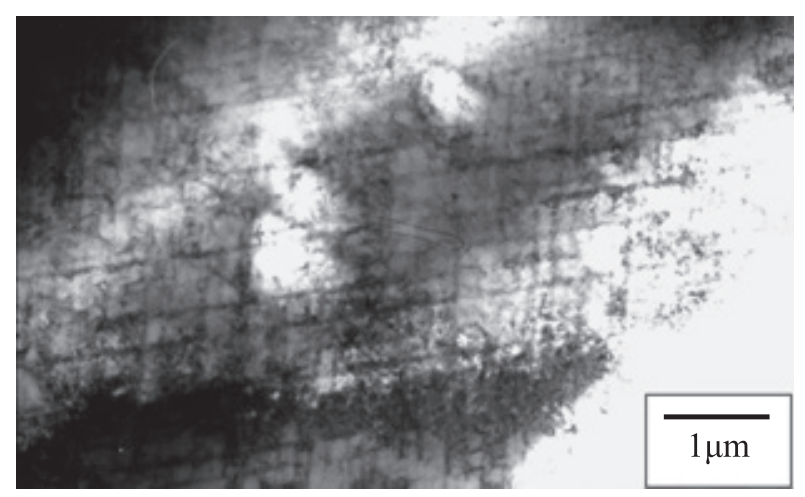

Fig.6 TEM structure of the $5 \%$ deformed compact held at $1200^{\circ} \mathrm{C}$ for $5 \mathrm{hrs}$.

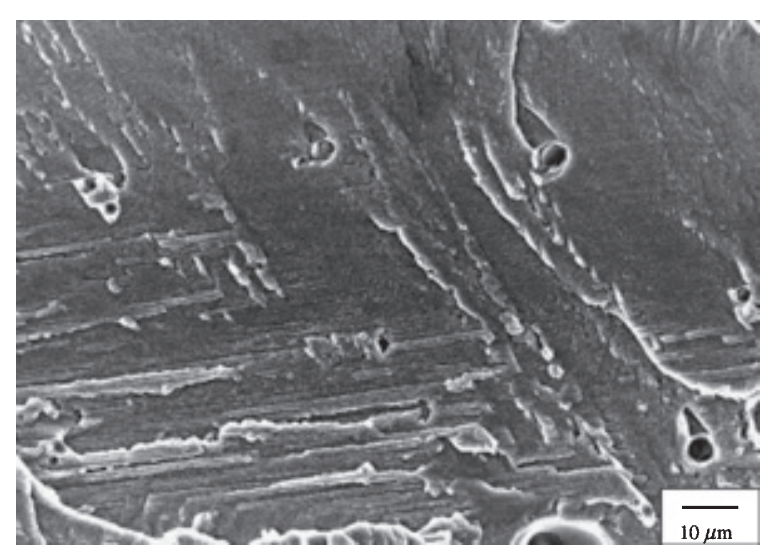

Fig.7 Fracture surface of the compact held at $1200^{\circ} \mathrm{C}$ for $20 \mathrm{hrs}$ tensile tested at $-196^{\circ} \mathrm{C}$.

nitrogen, lowering stacking fault energy and the formation of Lomer-Cottrell sessile dislocation ${ }^{6}$. Anyhow it can be expected that dislocations arrangements are planer. Fig. 6 shows transmission electron microstructure of the $5 \%$ tensile deformed compact that was held at $1200^{\circ} \mathrm{C}$ for 5 hrs. It can be seen that dislocations have become well aligned. The tensile test mentioned above was performed at room temperature. As the high nitrogen steels are reported to reveal low-temperature brittleness, tensile test was done at $-196^{\circ} \mathrm{C}$. Fracture occurred at an early elastic stage and fracture surface was almost perpendicular to the tensile axial. Fig. 7 shows the fracture surfaces of the compact held at $1200^{\circ} \mathrm{C}$ for $20 \mathrm{hrs}$. On the surface, sliplike bands (a) can be seen with an inclination of $60^{\circ}$ to each other and the facet plane is determined as (111) $\gamma$ by the shape of etch pit $(b)^{7)}$. The (111) plane is not only the slip plane but also twining plane for face center cubic crystal. Fig. 8 shows the irregularity of fracture surface examined by means of laser microscope. It is found that the fracture surface is very flat and normal to the tensile axis. The mechanism of low temperature embrittlement 


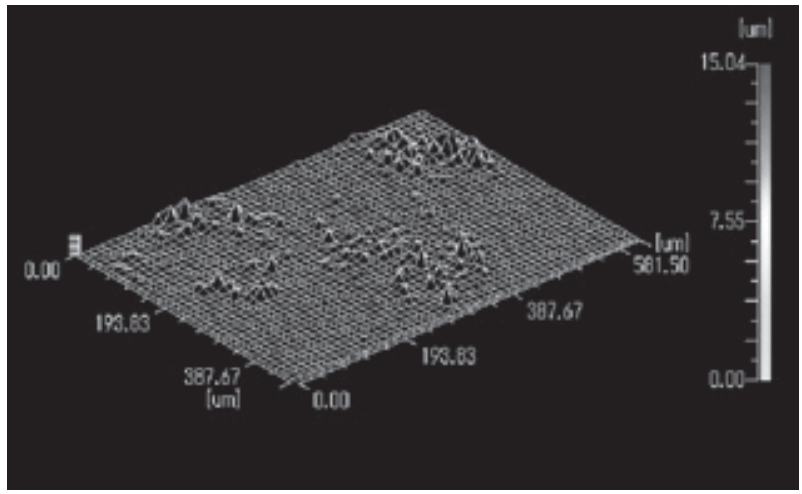

Fig. 8 The irregularity of fracture surface of the compact tensile fractured at $-196^{\circ} \mathrm{C}$.

of high nitrogen steels is recognized to be slip-off ${ }^{8)}$, however, the idea of occurring of the cleavage fracture is undeniable because twinning might occur on (111) plane which can be seen as slip bands in Fig. 7 in the same manner as $\alpha$ iron which causes cleavage fracture by deformation twining on (112) plane at low temperature. Impact test was performed to examine the low temperature mechanical behaviour. Fig. 9 shows the Charpy impact value as a function of testing temperature. Data of MIM'ed SUS316 (Fe-18Cr-12Ni-2Mo) and fine-grained compact are inserted in the same figure. As the depth of notch of the
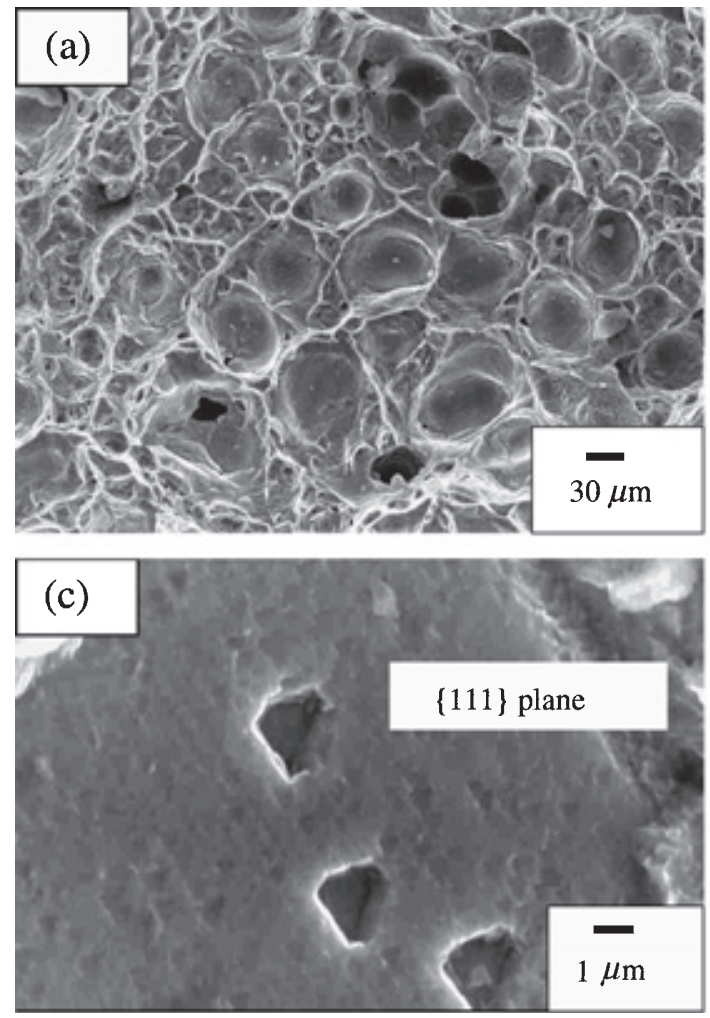

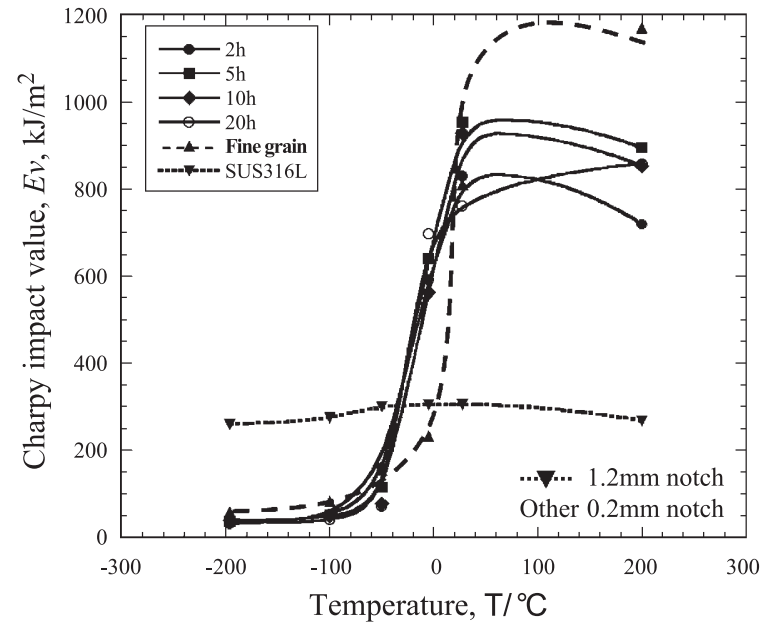

Fig.9 Results of Charpy impact test for high nitrogen steels and conventional SUS316.

specimen is different between high nitrogen steels and SUS316, the relative estimation is meaningless. Unlike the compared with SUS316, the impact behaviour of high nitrogen steels strongly depend on the test temperature and ductile-brittle transition behaviour can be seen clearly. The DBTT temperature is about $-20^{\circ} \mathrm{C}$ for every compact and that of fine-grained one is near $0^{\circ} \mathrm{C}$. Fig. 10 shows impact
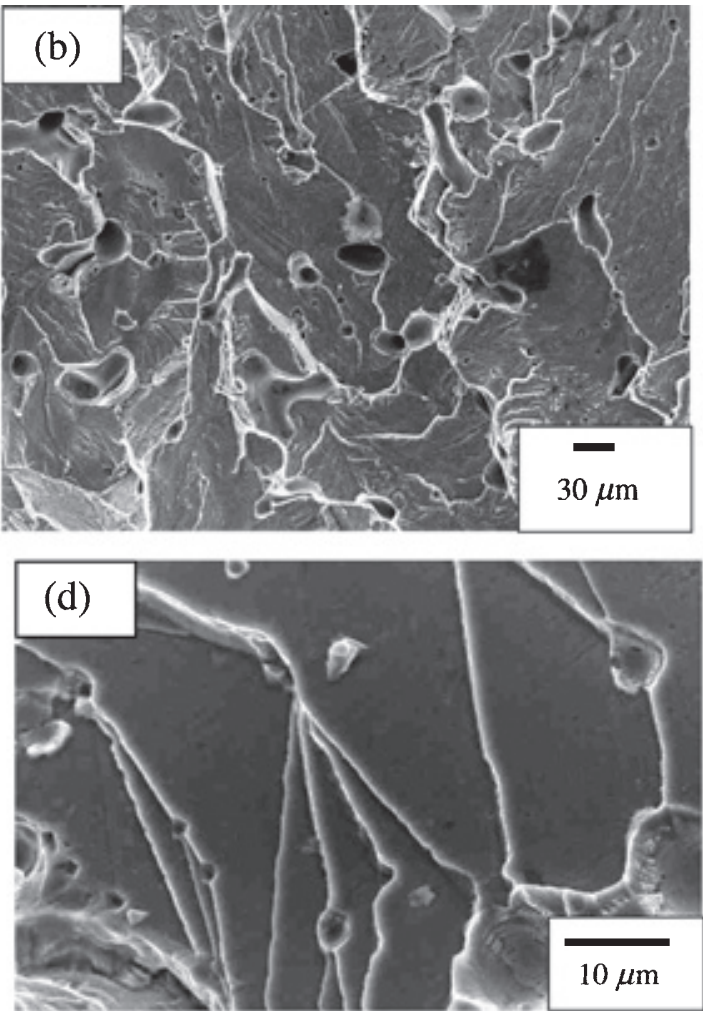

Fig.10 Impact fracture surfaces of compacts tested at $-5^{\circ} \mathrm{C}(\mathrm{a}),-196^{\circ} \mathrm{C}(\mathrm{b})$, and $-50^{\circ} \mathrm{C}(\mathrm{c}, \mathrm{d})$. From the etch pit morphology, fracture surface is identified to be (111) as shown in fig. (c). 
fracture surfaces for compacts held at $1200^{\circ} \mathrm{C}$ for $2 \mathrm{hrs}$. Above the DBTT, every compact surface is covered with dimple pattern. The surface of the compact fractured at $-5^{\circ} \mathrm{C}(\mathrm{a})$ is constructed of shallow dimple and brittle patterns. Below DBTT, fracture surfaces $(b, c, d)$ were covered with facet planes which are identified as (111) plane from the shape of etch pit. It is well known that the FCC materials except for Ir and Rh don't embrittle intrinsically at low temperature ${ }^{9)}$ and brittle fracture of the high nitrogen steels at low temperature is believed to be associated with slip-off of dislocations. However, cleavage fracture might occur for high nitrogen steels as mentioned above. Also refinening the grain size, DBTT is expected to be shifted to lower temperature like BCC crystals, however, DBTT of fine-grained compact is pushed up about $20^{\circ} \mathrm{C}$. These results require further investigation for understanding the mechanical behaviour of high nitrogen austenitic steels.

\section{Summary}

Microstructure and mechanical properties of high nitrogen steels containing $17 \mathrm{Cr}-12 \mathrm{Mn}-3 \mathrm{Mo}$ produced by means of metal injection moulding and nitrogen absorption methods were examined. The results obtained were as follows; High nitrogen austenitic stainless steels with high density could be produced by MIM method with careful heat treatment. The structure had uniform nitrogen distribution when heated at $1200^{\circ} \mathrm{C}$ for more than $5 \mathrm{hr}$ after sintering at $1300^{\circ} \mathrm{C}$ for $3 \mathrm{hr}$. Increasing the holding time at $1200{ }^{\circ} \mathrm{C}$, nitrogen content and lattice constant have increased and then nitrogen was saturated. Although the grain size of compacts was large, they revealed superior tensile properties at room temperature, for example, the yield and tensile strength were $758,1172 \mathrm{MPa}$, respectively with uniform elongation of $41 \%$ for the material whose holding time at $1200^{\circ} \mathrm{C}$ was $10 \mathrm{hrs}$. However, the mechanical properties at low temperature deteriorated and ductilebrittle transition behaviour appeared in the impact testing.
Fracture surfaces were constructed by flat facets like embrittled $\alpha$-iron. The facet plane was identified as (111) plane. And there were slip bands on the surface which might be considered to be deformation twining plane formed in front of crack. Ductile-brittle transition temperature of high nitrogen steels was about $-20^{\circ} \mathrm{C}$ for every compact.

\section{References}

1) P.J. Uggowitzer, W.F. Bäfre, H. Wohlfromm, and M. Speidel: "Nickel-Free High Nitrogen Austenitic Stainless steels $\cdots "$ ", Materials Science Forum, 318-320 (1999)663-672.

2) M. Fujikura, K. Takeda, and K. Ishida: "Effect of Manganese and Nitrogen on the Mechanical Properties ...", Transactions ISIJ, 15(1975)464-469.

3) Y. Katada: "Pressurized ESR Method", Bull. Iron Steel Inst. Jpn., 7(2002) 848-849.

4) Y. Kuroda, M. Komada, R. Murakami, S. Fukumoto, N. Tsuchida, Y. Harada, and K. Fukaura: "Metal injection molding method of Ni-free austenitic stainless steel II ...", Advanced Materials Research, 26-28 (2007) 15-18.

5) T. Tsuchiyama, N. Hirakawa, N. Nakada, and S. Takaki: "Microstructure and Deformability of (Ferrite $+\mathrm{Cr}_{2} \mathrm{~N}$ ) Eutectoid Structured High Nitrogen steel", CAMPISIJ, 20(2007)1132-1134.

6) Y. Tomota: The 190th Nishiyama memorial lecture, A new field of steels by nitrogen evolution, and its application, (2006)51-70.

7) M. Watanabe, Y. Mukai, M. Murata, and G. Tsujii: "Investigation of SCC Mechanism of SUS304 in Boiling $42 \% \mathrm{MgCl}_{2}$ Solution by Fractographic Observation", Zairyo, 27(1978)87-91.

8) Y. Tomota, Y. Xia, and K. Inoue: "Mechanism of Low Temperature Brittle Fracture in high Nitrogen Cearing Austenitic Steels", Acta mater., 46(1998)1577-1587.

9) T.H. Courtney: Mechanical behavior of materials, McGRAW-HILL INT'l EDITIONS, (1990)392. 